\title{
Semiconductor quantum dot-sensitized solar cells
}

\section{Jianjun $\operatorname{Tian}^{1 *}$ and Guozhong $\mathrm{Cao}^{2 \star}$}

\begin{abstract}
${ }^{1}$ Advanced Materials and Technology Institute, University of Science and Technology Beijing, Beijing, China; ${ }^{2}$ Department of Materials and Engineering, University of Washington, Seattle, WA, USA
\end{abstract}

Received: 12 August 2013; Revised: 5 October 2013; Accepted: 6 October 2013; Published: 31 October 2013

\section{Abstract}

Semiconductor quantum dots (QDs) have been drawing great attention recently as a material for solar energy conversion due to their versatile optical and electrical properties. The QD-sensitized solar cell (QDSC) is one of the burgeoning semiconductor QD solar cells that shows promising developments for the next generation of solar cells. This article focuses on recent developments in QDSCs, including 1) the effect of quantum confinement on QDSCs, 2) the multiple exciton generation (MEG) of QDs, 3) fabrication methods of QDs, and 4) nanocrystalline photoelectrodes for solar cells. We also make suggestions for future research on QDSCs. Although the efficiency of QDSCs is still low, we think there will be major breakthroughs in developing QDSCs in the future.

Keywords: quantum dot; solar cell; quantum dot-sensitized solar cell (QDSC); quantum confinement; multiple exciton generation (MEG); photoelectrode

T he establishment of low-cost and high-performance solar cells for sustainable energy sources to replace fossil fuels has become an urgent subject to scientists around the world $(1,2)$. Because traditional photovoltaic devices (i.e. the p-n junction silicon crystalline solar cells) suffer from high costs of manufacturing and installation, now the focus is on the next generation of solar cells with high efficiency at economically viable costs. As a cost-effective alternative to silicon-based photovoltaics, semiconductor quantum dot (QD)-sensitized solar cells (QDSCs) have attracted considerable attention recently and have shown promising developments for the next generation of solar cells (2-7). QDSCs can be regarded as a derivative of dye-sensitized solar cells (DSCs), which were first reported by O'Regan and Grätzel in 1991 (8). In DSCs, the sensitizer commonly uses organic dyes of ruthenium polypyridine complexes. To increase the light harvest in the visible light region,

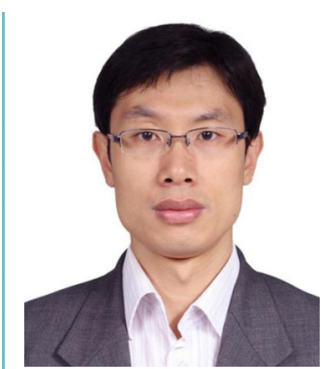

Jianjun Tian is an associate professor in the Advanced Materials and Technology Institute at University of Science and Technology Beijing, China. He earned a PhD degree in material science from this university in 2007. His current research focuses on quantum dots and their application for photovoltaic conversion devices.

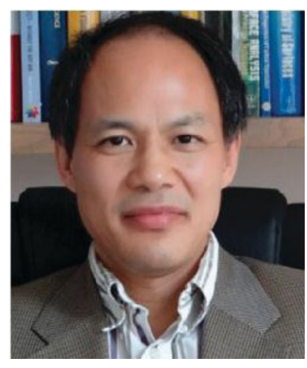

Guozhong Cao is the BoeingSteiner Professor of Materials Science and Engineering, professor of chemical engineering, and adjunct professor of mechanical engineering at University of Washington. He received his $\mathrm{PhD}$ degree from Eindhoven University of Technology in 1991. His current research focuses on the chemical processing of nanomaterials for energy-related applications, including solar cells, lithium-ion batteries, supercapacitors, and hydrogen storage.

many efforts have been made to focus on the development of high-performance sensitizers (9-12). It has always been a challenge to obtain an ideal organic dye as a sensitizer to absorb photons in the full sunlight spectra. For this reason, narrow-band-gap semiconductor QDs, such as CdS (13, 14), CdSe $(15,16), \operatorname{PbS}(17)$, and InAs (18), have been used as the photosensitizer instead of organic dyes due to their versatile optical and electrical properties (19-22), including: 1) a tunable band gap depending on the QD size, 2) a larger extinction coefficient, 3) higher stability toward water and oxygen, and 4) multiple exciton generation (MEG) with single-photon absorption (23-25). The theoretical photovoltaic conversion efficiency of QDSCs can reach up to $42 \%$ in view of the 
MEG effect of QDs. Such efficiency is much higher than the rate of $31 \%$ for semiconductor solar cells according to the Schockley-Queisser limit (26).

Figure 1(a) shows the cell structure of a QDSC, which consists of a wide-band-gap mesoporous oxide film (a photoelectrode, such as the commonly used $\mathrm{TiO}_{2}$ or $\mathrm{ZnO}$ ), QDs (the sensitizer), an electrolyte, and a counterelectrode. During operation, photons are captured by QDs, yielding electron-hole pairs that are rapidly separated into electrons and holes at the interface between the nanocrystalline oxide and QDs. The electrons jump into the oxide film, and the holes are released by redox couples in the electrolyte. Figure 1(b) shows photoinduced charge transfer processes employing $\mathrm{S}^{2-} / \mathrm{Sn}^{2-}$ as the redox couple (7): 1) charge injection from an excited QD into $\left.\mathrm{TiO}_{2}, 2\right)$ transport of electrons to the collecting electrode surface, 3) hole transfer to the redox couple, 4) regeneration of the redox couple, 5) recombination of electrons from the QD and the oxidized form of the redox couple, and 6) interfacial recombination of electrons from $\mathrm{TiO}_{2}$ and the oxidized form of the redox couple. Kamat group's works reported $(27,28)$ that the electron transfer between QD and $\mathrm{TiO}_{2}$ was an ultrafast process with a rate constant of the order of $10^{10} \sim 10^{11} \mathrm{~s}^{-1}$, which was faster than that of hole transfer $\left(10^{7} \sim 10^{9} \mathrm{~s}^{-1}\right)$. However, electron transport within the mesoporous $\mathrm{TiO}_{2}$ film is slower than that of electron and hole transfers. So the recombination losses become a major factor in limiting the overall efficiency.

\section{Quantum confinement effect for QDSCs}

QDs are extremely small semiconductor nanocrystals with a size comparable to the Bohr radius of an exciton (29). For most semiconductors, the Bohr radius of an exciton is in the range of $1 \sim 10 \mathrm{~nm}$ : for example, it is 4.2 $\mathrm{nm}$ for $\mathrm{Si}, 3.1 \mathrm{~nm}$ for $\mathrm{CdS}, 6.1 \mathrm{~nm}$ for $\mathrm{CdSe}$, and $2.2 \mathrm{~nm}$ for $\mathrm{ZnO}$. However, the Bohr radius of the exciton is very large for some semiconductors: it is $20.4 \mathrm{~nm}$ for $\mathrm{PbS}, 46$ $\mathrm{nm}$ for $\mathrm{PbSe}$, and $67.5 \mathrm{~nm}$ for InSb. Due to the dimension effect, the behavior of electrons in QDs differs from that in the corresponding bulk material, which is called the 'quantum confinement effect'. A semiconductor with a larger excitonic Bohr radius means that the QDs made from the material may achieve a strong confinement effect more easily. Because of the quantum confinement effect, the band gap energy $\left(E_{g}\right)$ of QD increases with the decrease of particle size (30-32). $E_{g}$ can be elucidated by $E_{g} \propto 1 / r^{2}$, where $r$ is the radius of QD (29). The increase of $E_{\mathrm{g}}$ means that more energy will be needed in order to be absorbed by the QD. So the range of optical absorption wavelengths of QD can be tuned by controlling the size of QD. Such a feature of QDs with tunable $E_{g}$ has led to their applications in light-emitting diodes (LEDs) for full-color displays (33), and in QD-sensitized solar cells for the generation of optical absorption at desired wavelengths $(34,35)$.

Ref. (36) has demonstrated that the conduction band energy $\left(E_{\mathrm{cb}}\right)$ of QD would move up the high energy level by decreasing particle size due to the quantum confinement effect, which is very significant to solar cells. As shown in Fig. 2(a), the $E_{\mathrm{cb}}$ of bulk $\mathrm{PbS}$ is $-4.74 \mathrm{eV}$, which is lower than that of $\mathrm{TiO}_{2}(-4.21 \mathrm{eV})$. The electrons in the conduction band of bulk $\mathrm{PbS}$ is difficult to jump into the conduction band of $\mathrm{TiO}_{2}$. The $E_{\mathrm{g}}$ of $\mathrm{PbS}$ can be increased by reducing its particle size, as shown in Fig. 2(b), leading to the conduction band minimum shift to higher energy. When the conduction band energy of $\mathrm{PbS}$ matches that of $\mathrm{TiO}_{2}$, the electrons divided from exciton pairs by photons can easily transfer from the conduction band in $\mathrm{PbS}$ into the conduction band in $\mathrm{TiO}_{2}$. So the quantum confinement effect is the necessary condition for the construction of QDSCs. For QDSCs, smaller QDs are preferred in order to possibly achieve more QDs adsorbed on the photoelectrode film. Smaller QDs have also demonstrated a higher electron injection rate than their larger counterparts. Figure 3 shows the dependence of the electron transfer rate constant on the energy difference between the conduction

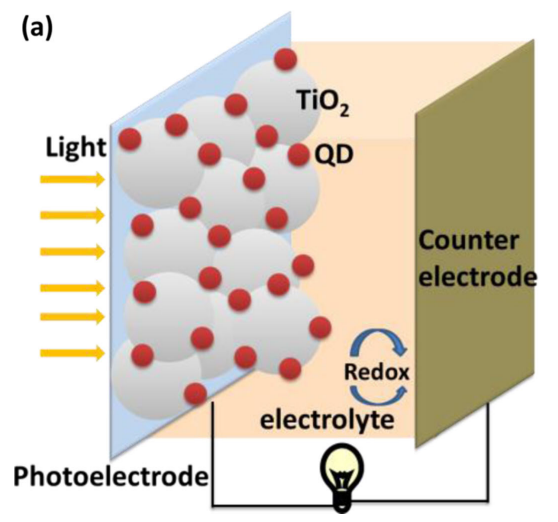

(b)

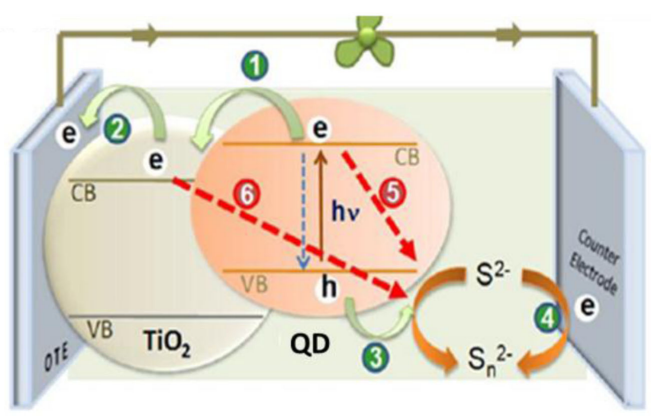

Fig. 1. (a) Schematic illustration of the structure of a quantum dot-sensitized solar cell (QDSC); and (b) schematic illustration of photoinduced charge transfer processes following a laser pulse excitation (7). 

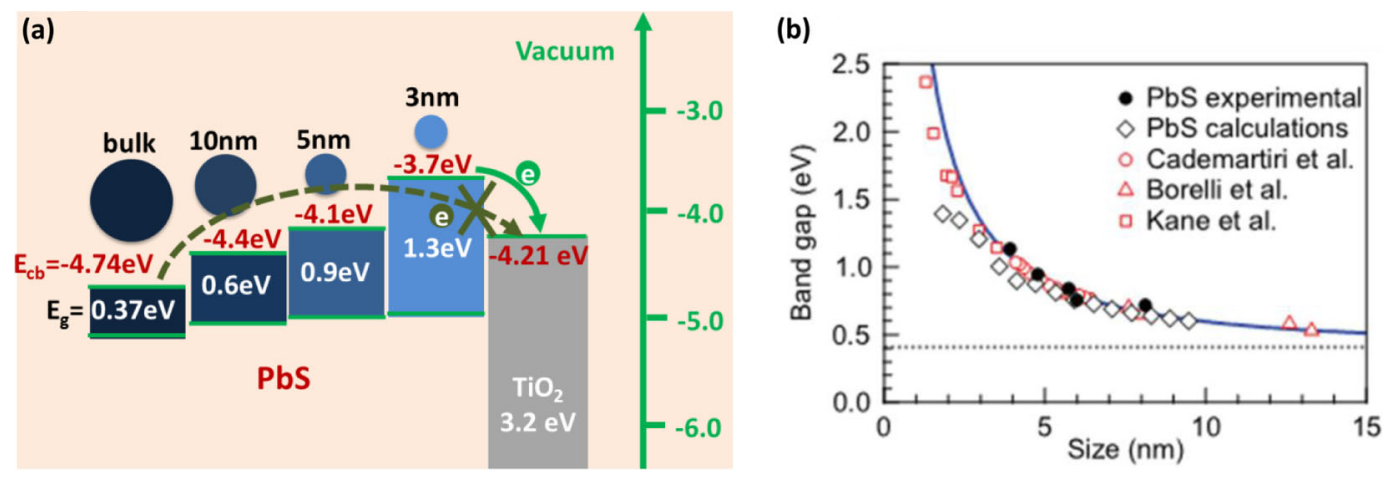

Fig. 2. (a) Schematic illustration of the modulation of energy levels of $\mathrm{PbS}$ by particle size; and (b) relationship between the $\mathrm{PbS}$ $E_{\mathrm{g}}$ and particle size, as reported in Refs. $(31,32)$.

bands and the principle of electron transfer from two different-sized CdSe QDs into a $\mathrm{TiO}_{2}$ nanoparticle (26). It can be seen that the electron transfer rate evidently increases with decreasing QD size in the $\mathrm{CdSe}-\mathrm{TiO}_{2}$ system. For QDs, the increase of band gap would be expected to have favorable conduction band energies for injecting electrons into a photoelectrode. However, the increase of $E_{\mathrm{g}}$ indicates that only high energy photons can be absorbed by the QD, leading to the absorption wavelength edge of the QD blue shift as shown in Fig. 4. Too small QDs will lead to too much low the optical absorption for the photoelectrodes, which has negative impacts on the solar cells. Therefore, the best solar-toelectricity conversion efficiency can be obtained by optimizing the band energy structure of QDs to match the oxide film and obtain a wide optical absorption wavelength.

Table 1 shows the energy band parameters of QDs and oxides, which are usually chosen to fabricate QDSCs. The principles for choosing materials to construct solar cells are as follows: 1) optical absorption is primarily determined by the band gap of active materials, and therefore

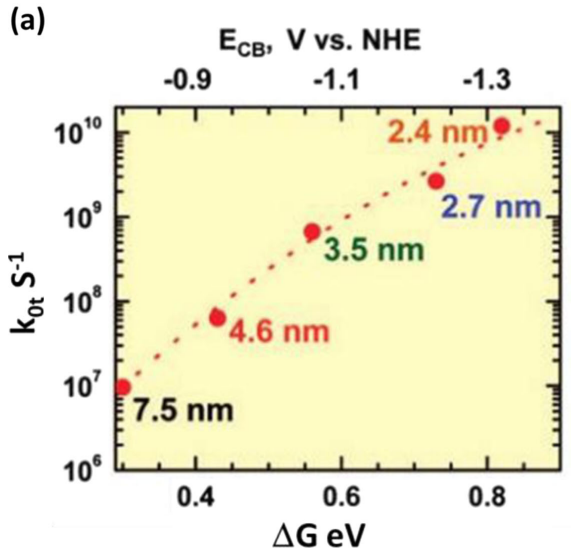

the materials with narrow and direct band gaps are preferred; and 2) the device structure should be designed by choosing materials with well-matched energy levels that may establish a suitable energy gradient, allowing the charges to transport highly efficiently within the solar cell (29).

\section{The MEG effect for QD-sensitized solar cells}

MEG in QDs has been considered another way to enhance the power conversion efficiency of QDSCs by utilizing the excess energy in the absorbed photons. The MEG effect is that two or more electron-hole pairs (excitons) are generated by one photon excitation, in contrast with the conventional case where one photon excitation can produce only a single exciton. In theory, the MEG effect requires a photon with energy at least twice that of the band gap of the QDs. In view of the MEG effect, the theoretic power conversion efficiency of QDSC has been predicted to be as high as $42 \%$, which is higher than the Shockley-Queisser efficiency limit of $31 \%$, for the traditional single-junction solar cells (40). The experimental study of Semonin (41) has proven the

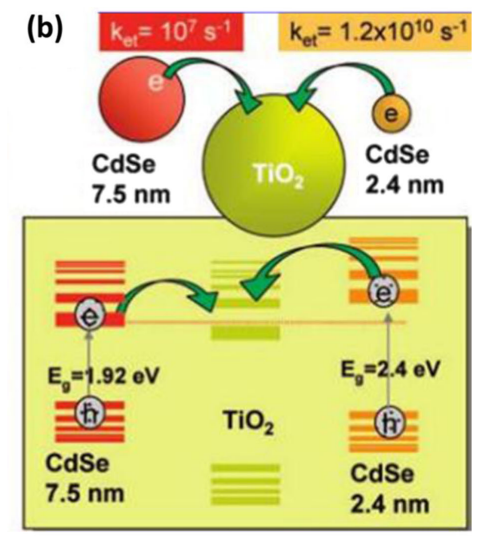

Fig. 3. (a) The dependence of the electron transfer rate constant on the energy difference between the conduction bands;

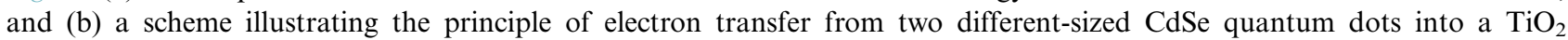
nanoparticle (26). 


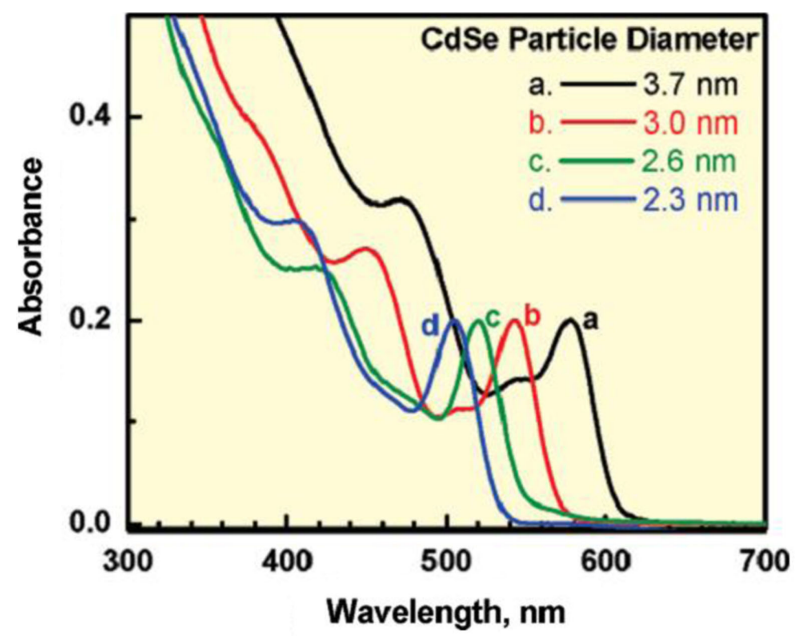

Fig. 4. Absorption spectra of 3.7, 3.0, 2.6, and $2.3 \mathrm{~nm}$ diameter CdSe quantum dots in toluene; from Ref. (37).

feasibility of this concept, with the demonstration of an external quantum efficiency greater than $100 \%$ at wavelengths below $400 \mathrm{~nm}$ on a p-n junction solar cell based on a layer of PbSe QDs deposited on $\mathrm{ZnO}$ thin film. So the utilization of high-energy photons to generate multiple excitons or capture hot electrons before their thermalization can boost the operational efficiency of QDSC (7).

The MEG effect is a phenomenon that can also be observed in a bulk semiconductor. However, the required threshold for the energy of photons is much higher than that in QDs. For the semiconductor PbSe, the threshold energy of bulk material is as high as $6.5 E_{\mathrm{g}}$, whereas it is about 3.4 $E_{\mathrm{g}}$ of $\mathrm{PbSe} \mathrm{QD}\left(E_{\mathrm{g}}\right.$ is the energy band gap of the PbSe). The possibility of enhanced MEG in QDs was first proposed in 2001, and the original concept is shown in Fig. 5 (40). The possible reasons for the MEG effect, which can be achieved easily in QDs, have been attributed

Table 1. Energy band parameters of some of the most commonly used materials for QDSCs $(38,39)$

\begin{tabular}{lccc}
\hline Semiconductors & $\begin{array}{c}\text { Band } \\
\text { gap (eV) }\end{array}$ & $\begin{array}{c}\text { Conduction band } \\
\text { minimum }(\mathrm{eV})\end{array}$ & $\begin{array}{c}\text { Valence band } \\
\text { maximum (eV) }\end{array}$ \\
\hline $\mathrm{CdS}$ & 2.40 & -3.98 & -6.38 \\
$\mathrm{CdSe}$ & 1.74 & -4.10 & -5.84 \\
$\mathrm{PbS}$ & 0.37 & -4.74 & -5.11 \\
$\mathrm{PbSe}$ & 0.27 & -4.93 & -5.20 \\
$\mathrm{ZnS}$ & 3.60 & -3.46 & -7.06 \\
$\mathrm{ZnSe}$ & 2.70 & -3.40 & -6.10 \\
$\mathrm{CulnS}$ & 1.50 & -4.06 & -5.56 \\
$\mathrm{TiO}_{2}$ & 3.20 & -4.21 & -7.41 \\
$\mathrm{ZnO}$ & 3.20 & -4.19 & -7.39 \\
$\mathrm{SnO}_{2}$ & 3.50 & -4.50 & -8.00 \\
\hline
\end{tabular}

to the following (40): 1) the electron-hole $\left(\mathrm{e}^{-}-\mathrm{h}^{+}\right)$pairs are correlated and thus exist as excitons rather than free carriers; 2) the rate of hot electron and hole cooling can be slowed because of the formation of discrete electronic states; 3) momentum is not a good quantum number, and thus the need to conserve crystal momentum is relaxed; and 4) auger processes are greatly enhanced because of the increased $\mathrm{e}^{-}-\mathrm{h}^{+}$Coulomb interaction. So the production of multiple exciton pairs in QDs can be enhanced in comparison with bulk semiconductors.

MEG in QDs is a very important process that, if harnessed, can lead to a new solar conversion efficiency limit (42). Although reasonably high and reliable MEG efficiencies have now been reported, no QD-based solar cells have yet shown enhanced conversion efficiency due to MEG effects (40). So the achievement of QD solar cells with MEG effect enhancement is still facing a huge challenge, partially because the excitation of the MEG effect requires photons with relatively high energy and a pump light with high power density (29). To make the largest impact on solar energy technologies, the MEG efficiency needs to be further improved so that the onset of MEG occurs as close to $2 E_{\mathrm{g}}$ as possible (42).

\section{Fabrication methods of QDs for the solar cells}

In a typical process for the fabrication of QDSC photoelectrodes, QDs can be introduced via two approaches: 1) in situ growth directly from precursor solutions, and 2) adsorption of pre-synthesized QDs with or without a bifunctional linker. However, the QDSCs produced by the latter approach have relatively low conversion efficiency, largely due to the difficulty in achieving sufficient coverage of QDs (15). The former (i.e. in situ growth of QDs) includes chemical bath deposition (CBD) (43) and successive ionic layer absorption and reaction (SILAR) (24, 44), and it has been shown to perform better than the latter when being adopted to assemble QDSCs (45). The CBD is a relatively simple method to deposit QDs and nanoparticle films, and it possesses many advantages, such as stable yieldings, robust adherence, and uniform and good reproducibility. The growth of QDs strongly depends on the growth conditions, such as the duration of deposition, composition and temperature of the solution, and characteristics of the mesoporous films. The SILAR method is based on successive reactions on the surface oxides. Each reaction is followed by rinsing, which enables a heterogeneous reaction between the solid phase and the solvated ions in the solution. So a thin film can be grown layer by layer. Figure 6 shows the schematic illustration of the formation process of $\mathrm{CdS}-\mathrm{CdSe} \mathrm{QD}$ co-sensitized solar cells. The $\mathrm{CdS}$ and $\mathrm{CdSe}$ on a $\mathrm{TiO}_{2}$ mesoporous film are synthesized by the SILAR and CBD methods, respectively. The QDSCs assembled with a $\mathrm{TiO}_{2}$ mesoporous film, CdS-CdSe QDs, a polysulfide electrolyte, 


\section{Enhanced Photovoltaic Efficiency in Quantum Dot Solar Cells by Multiple Exciton Generation (MEG)}

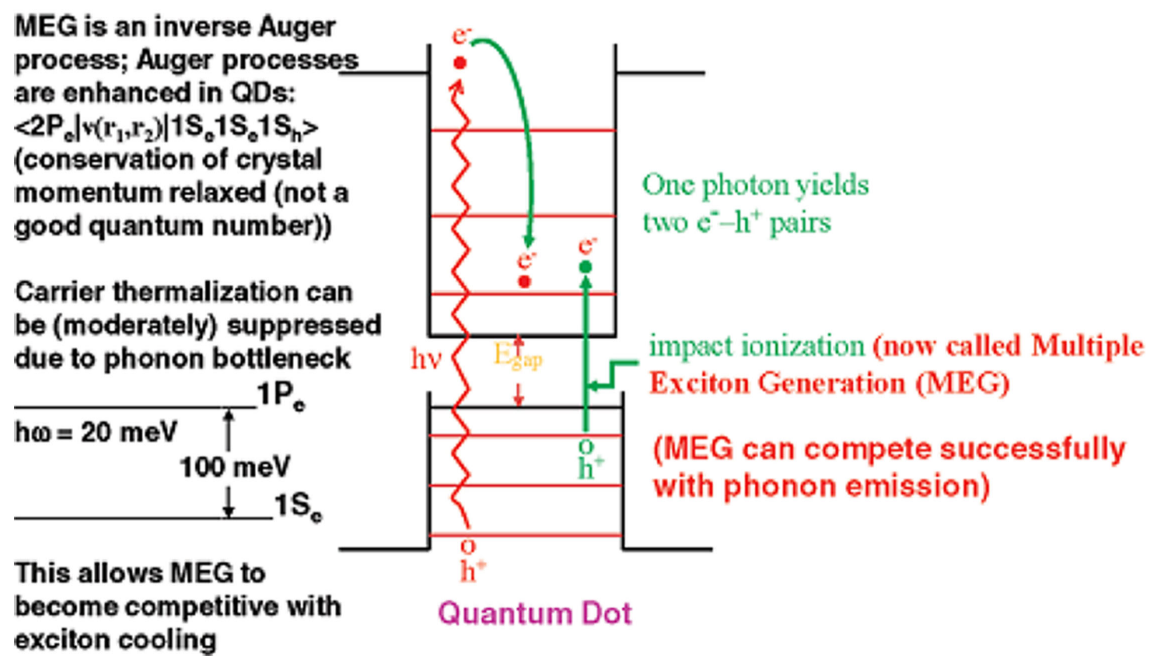

Fig. 5. Multiple exciton generation in quantum dots (40).

and a $\mathrm{Cu}_{2} \mathrm{~S}$ counter-electrode exhibit a high power conversion efficiency of $4.62 \%(25)$.

\section{Nanocrystalline photoelectrodes for solar cells}

As wide-band-gap semiconductors for the sensitizer scaffold, conventional $\mathrm{TiO}_{2}$ and $\mathrm{ZnO}$ porous nanocrystalline films had been used in QDSCs due to the large surface area available for QD adsorption. $\mathrm{TiO}_{2}$ is commonly chosen as the photoelectrode of QDSCs, and it exhibits high power conversion efficiency $(\sim 5 \%)$. For example, the research of Hossain et al. (46) showed that CdSesensitized $\mathrm{TiO}_{2}$ solar cells incorporating light-scattering layers presented a power conversion efficiency of $5.21 \%$. Kamat et al. reported that QDSCs with Mn-doped CdSCdSe on the $\mathrm{TiO}_{2}$ film achieved a power conversion efficiency of 5.4\% (3). Lee et al. (47) developed a $\mathrm{PbS}-\mathrm{Hg}$
QD-sensitized $\mathrm{TiO}_{2}$ solar cell with an unprecedentedly high power conversion efficiency of $5.6 \%$.

$\mathrm{ZnO}$ is a good alternative to $\mathrm{TiO}_{2}$ because it possesses energy-band structure and physical properties that are similar to those of $\mathrm{TiO}_{2}$. But it has an electronic mobility $\sim 4$ times higher than that of $\mathrm{TiO}_{2}$ (48-50). In addition, $\mathrm{ZnO}$ is easy to form anisotropic structures (such as nanowires, nanorods, and nanotubes), which presents unique electronic and optical properties $(51,52)$. Furthermore, a photoelectrode film constructed with these nanostructures is helpful for the distribution of QDs (25). ZnOnanostructured photoelectrodes for QDSCs have been investigated over the last several years (53-57). However, the efficiency of $\mathrm{ZnO}$-based QDSCs is lower than that of $\mathrm{TiO}_{2}$-based devices, which is likely due to the high surface charge recombination in $\mathrm{ZnO}(58,59)$. The high surface charge recombination can be attributed to many defects of
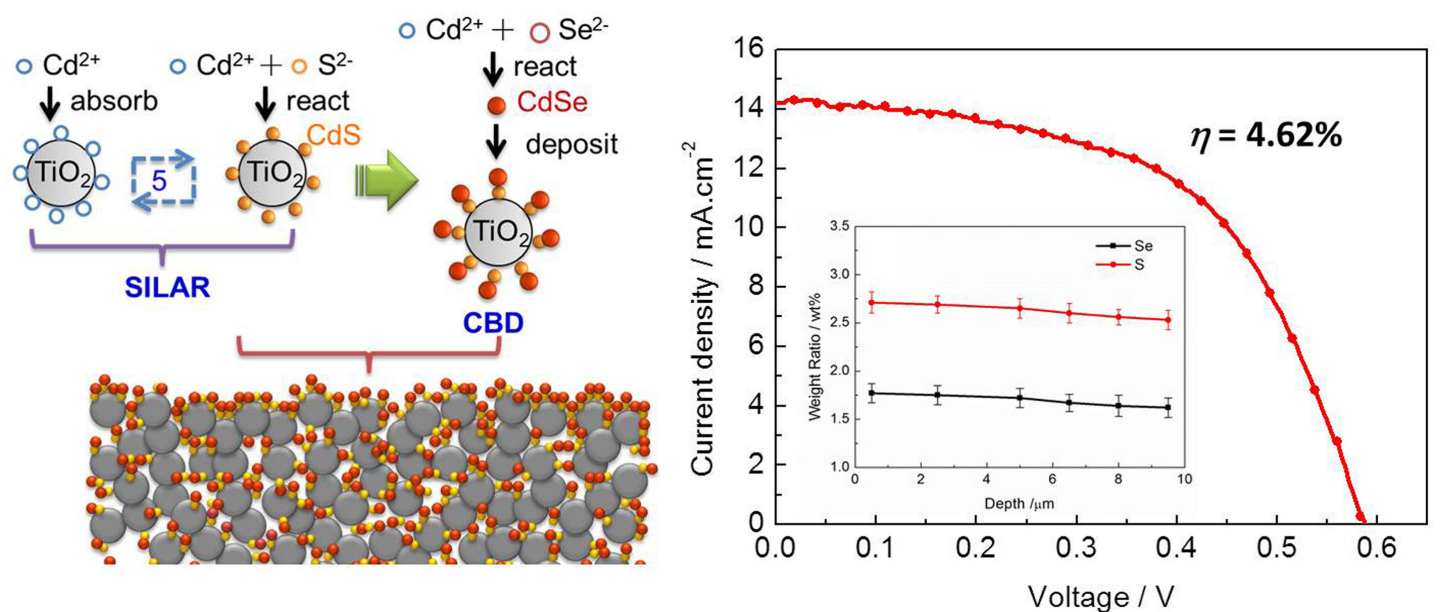

Fig. 6. Sketch of the formation of CdS-CdSe QDs on mesoporous $\mathrm{TiO}_{2}$ film and the J-V curve of QDSCs. 
the $\mathrm{ZnO}$ surface. In addition, the chemical stability of $\mathrm{ZnO}$ is less than that of $\mathrm{TiO}_{2}$, which makes it easy for $\mathrm{ZnO}$ to react with the electrolyte (60). Tian et al. (61) developed a facile passivation strategy for $\mathrm{ZnO}$ mesoporous photoelectrodes. This method not only opened the apertures to improve the distribution of QDs in the photoelectrodes, increased the specific surface area, and reduced the surface defects of the $\mathrm{ZnO}$ photoelectrodes to accommodate more QDs, but also suppressed the charge recombination and prolonged the electron lifetime by introducing a barrier layer. As a result, a record power conversion efficiency of 4.68\% for ZnO-based QDSCs was obtained. Figure 7(a) and 7(b) show the transmission electron microscopy (TEM) and high-resolution TEM images of the passivated $\mathrm{ZnO}$ loaded with QDs, showing the passivated $\mathrm{ZnO}$ coated by $\mathrm{TiO}_{2}$ and $\mathrm{CdS}-\mathrm{CdSe}$ QDs that are $4-6 \mathrm{~nm}$ in size. In addition, this passivation strategy can also be applied in $\mathrm{ZnO}$ nanowires to enhance their performance (as shown in Fig. 7(c)-(f)) (62).
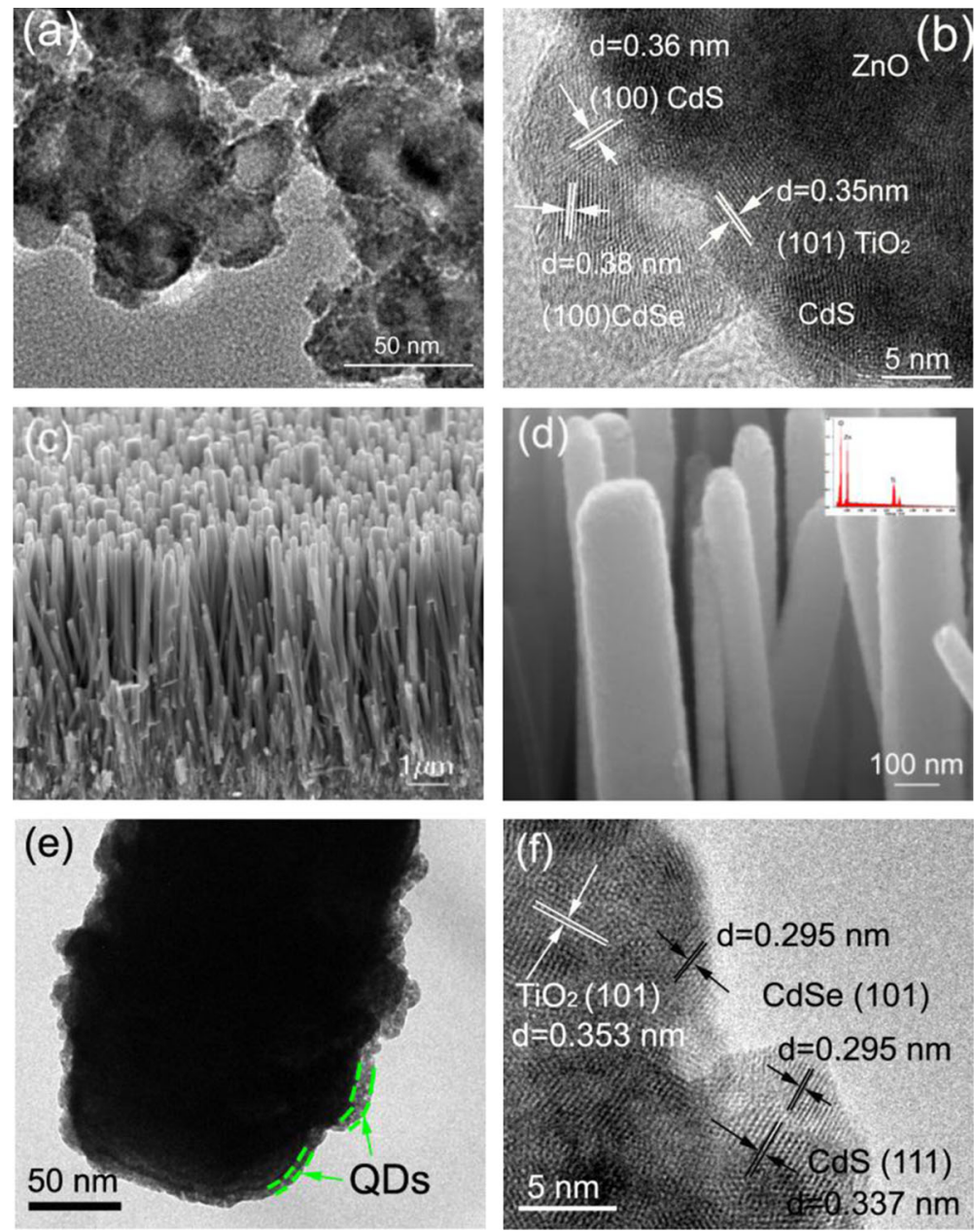

Semiconductor QDs have been drawing great attention recently as a material for solar energy conversion due to their high absorption coefficient, quantum confinement (tunable band gap), and MEG effects. QDSCs are burgeoning semiconductor QD solar cells that show promising developments for the next generation of solar cells. Future works should focus on improving the performance of the solar cells as follows: 1) designing new semiconductor QDs with a large wavelength range of optical absorption in terms of quantum confinement; 2) getting MEG effect enhancement of QDs by reducing the threshold energy; and 3) constructing suitable porosity for photoelectrodes to load more QDs and decrease the charge recombination. However, QDSCs are still in their infancy and face huge challenges in their development. With the recent advances in the study of semiconductor QDs, we expect major breakthroughs in developing QDSCs in the future. 


\section{Conflict of interest and funding}

There is no conflict of interest in the present study for any of the authors. This work was supported by the National Science Foundation of China (51374029, 51004011 and 51174247) and the Fundamental Research Funds for the Central Universities (FRF-TP-12-153A).

\section{References}

1. Graetzel M, Janssen RAJ, Mitzi DB, Sargent EH. Materials interface engineering for solution-processed photovoltaics. Nature 2012; 488: 304-12.

2. Tada H, Fujishima M, Kobayashi H. Photodeposition of metal sulfide quantum dots on titanium(IV) dioxide and the applications to solar energy conversion. Chem Soc Rev 2011; 40: 4232-43.

3. Santra PK, Kamat PV. Mn-doped quantum dot sensitized solar cells: a strategy to boost efficiency over 5\%. J Am Chem Soc 2012; 134: 2508-11.

4. Hossain MA, Jennings JR, Koh ZY, Wang Q. Carrier generation and collection in $\mathrm{CdS} / \mathrm{CdSe}$-sensitized $\mathrm{SnO} 2$ solar cells exhibiting unprecedented photocurrent densities. Acs Nano 2011; 5: 3172-81.

5. Ryu J, Lee SH, Nam DH, Park CB. Rational design and engineering of quantum-dot-sensitized $\mathrm{TiO} 2$ nanotube arrays for artificial photosynthesis. Adv Mater 2011; 23: 1883-8.

6. Sugaya T, Numakami O, Oshima R, Furue S, Komaki H, Amano T, et al. Ultra-high stacks of InGaAs/GaAs quantum dots for high efficiency solar cells. Energy Environ Sci 2012; 5: 6233-7.

7. Kamat PV. Quantum dot solar cells. The next big thing in photovoltaics. J Phys Chem Lett 2013; 4: 908-18.

8. Oregan B, Gratzel M. A low-cost, high-efficiency solar-cell based on dye-sensitized colloidal $\mathrm{TiO}_{2}$ films. Nature 1991; 353: $737-40$.

9. Bessho T, Yoneda E, Yum JH, Guglielmi M, Tavernelli I, Imai $\mathrm{H}$, et al. New paradigm in molecular engineering of sensitizers for solar cell applications. J Am Chem Soc 2009; 131: 5930-4.

10. Bomben PG, Robson KCD, Sedach PA, Berlinguette CP. On the viability of cyclometalated $\mathrm{Ru}(\mathrm{II})$ complexes for light-harvesting applications. Inorg Chem 2009; 48: 9631-43.

11. Johansson PG, Rowley JG, Taheri A, Meyer GJ. Longwavelength sensitization of $\mathrm{TiO} 2$ by ruthenium diimine compounds with low-lying pi* orbitals. Langmuir 2011; 27: 14522-31.

12. Zhao HC, Harney JP, Huang YT, Yum JH, Nazeeruddin MK, Gratzel $\mathrm{M}$, et al. Evaluation of a ruthenium oxyquinolate architecture for dye-sensitized solar cells. Inorg Chem 2012; 51: $1-3$.

13. Kim J, Choi H, Nahm C, Moon J, Kim C, Nam S, et al. The effect of a blocking layer on the photovoltaic performance in CdS quantum-dot-sensitized solar cells. J Power Sources 2011; 196: 10526-31.

14. Panigrahi S, Basak D. Morphology driven ultraviolet photosensitivity in $\mathrm{ZnO}-\mathrm{CdS}$ composite. J Colloid Interface Sci 2011; 364: 10-7.

15. Robel I, Subramanian V, Kuno M, Kamat PV. Quantum dot solar cells. Harvesting light energy with CdSe nanocrystals molecularly linked to mesoscopic $\mathrm{TiO}_{2}$ films. J Am Chem Soc 2006; 128: 2385-93.

16. Shen Q, Kobayashi J, Diguna LJ, Toyoda T. Effect of $\mathrm{ZnS}$ coating on the photovoltaic properties of CdSe quantum dotsensitized solar cells. J Appl Phys 2008; 103: 084304.
17. Plass R, Pelet S, Krueger J, Gratzel M, Bach U. Quantum dot sensitization of organic-inorganic hybrid solar cells. J Phys Chem B 2002; 106: 7578-80.

18. Yu P, Zhu K, Norman AG, Ferrere S, Frank AJ, Nozik AJ. Nanocrystalline $\mathrm{TiO} 2$ solar cells sensitized with InAs quantum dots. J Phys Chem B 2006; 110: 25451-4.

19. Bang JH, Kamat PV. Solar cells by design: photoelectrochemistry of $\mathrm{TiO} 2$ nanorod arrays decorated with CdSe. Adv Funct Mater 2010; 20: 1970-6.

20. Gonzalez-Pedro V, Xu X, Mora-Sero I, Bisquert J. Modeling high-efficiency quantum dot sensitized solar cells. Acs Nano 2010; 4: 5783-90.

21. Yu X-Y, Liao J-Y, Qiu K-Q, Kuang D-B, Su C-Y. Dynamic study of highly efficient CdS/CdSe quantum dot-sensitized solar cells fabricated by electrodeposition. Acs Nano 2011; 5: 9494-500.

22. Cheng CW, Karuturi SK, Liu LJ, Liu JP, Li HX, Su LT, et al. Quantum-dot-sensitized $\mathrm{TiO} 2$ inverse opals for photoelectrochemical hydrogen generation. Small 2012; 8: 37-42.

23. Zhu G, Pan L, Xu T, Sun Z. CdS/CdSe-cosensitized TiO2 photoanode for quantum-dot-sensitized solar cells by a microwave-assisted chemical bath deposition method. Acs Appl Mater Inter 2011; 3: 3146-51.

24. Lee YL, Lo YS. Highly efficient quantum-dot-sensitized solar cell based on Co-sensitization of CdS/CdSe. Adv Funct Mater 2009; 19: 604-9.

25. Tian JJ, Gao R, Zhang QF, Zhang SG, Li YW, Lan JL, et al. Enhanced performance of CdS/CdSe quantum dot cosensitized solar cells via homogeneous distribution of quantum dots in $\mathrm{TiO}_{2}$ film. J Phys Chem C 2012; 116: 18655-62.

26. Kamat PV. Quantum dot solar cells. Semiconductor nanocrystals as light harvesters. J Phys Chem C 2008; 112: 18737-53.

27. Tvrdy K, Frantsuzov PA, Kamat PV. Photoinduced electron transfer from semiconductor quantum dots to metal oxide nanoparticles. Proc Natl Acad Sci U S A 2011; 108: 29-34.

28. Chakrapani V, Baker D, Kamat PV. Understanding the role of the sulfide redox couple (S2-/S-n(2-)) in quantum dot-sensitized solar cells. J Am Chem Soc 2011; 133: 9607-15.

29. Zhang Q, Uchaker E, Candelaria SL, Cao G. Nanomaterials for energy conversion and storage. Chem Soc Rev 2013; 42: 3127-71.

30. Baskoutas S, Terzis AF. Size-dependent band gap of colloidal quantum dots. J Appl Phys 2006; 99: 013708.

31. Segets D, Lucas JM, Taylor RNK, Scheele M, Zheng H, Alivisatos AP, et al. Determination of the quantum dot band gap dependence on particle size from optical absorbance and transmission electron microscopy measurements. Acs Nano 2012; 6: 9021-32.

32. Moreels I, Lambert K, Smeets D, De Muynck D, Nollet T, Martins JC, et al. Size-dependent optical properties of colloidal PbS quantum dots. Acs Nano 2009; 3: 3023-30.

33. Wood V, Bulović V. Colloidal quantum dot light-emitting devices. Nano Rev 2010; 1: 5202.

34. Panzer MJ, Aidala KE, Bulović V. Contact printing of colloidal nanocrystal thin films for hybrid organic/quantum dot optoelectronic devices. Nano Rev 2012; 3: 16144.

35. Shibu E, Sonoda A, Tao Z, Feng Q, Furube A, Masuo S, et al. Energy materials: supramolecular nanoparticles for solar energy harvesting. Nano Rev 2013; 4: 2107.

36. Lee JRI, Meulenberg RW, Hanif KM, Mattoussi H, Klepeis JE, Terminello LJ, et al. Experimental observation of quantum confinement in the conduction band of CdSe quantum dots. Phys Rev Lett 2007; 98: 146803.

37. Kongkanand A, Tvrdy K, Takechi K, Kuno M, Kamat PV. Quantum dot solar cells. Tuning photoresponse through size 
and shape control of $\mathrm{CdSe}-\mathrm{TiO} 2$ architecture. $\mathrm{J}$ Am Chem Soc 2008; 130: 4007-15.

38. $\mathrm{Xu} \mathrm{Y,} \mathrm{Schoonen} \mathrm{MAA.} \mathrm{The} \mathrm{absolute} \mathrm{energy} \mathrm{positions} \mathrm{of}$ conduction and valence bands of selected semiconducting minerals. Am Mineral 2000; 85: 543-56.

39. Kim SH, Markovich G, Rezvani S, Choi SH, Wang KL, Heath JR. Tunnel diodes fabricated from CdSe nanocrystal monolayers. Appl Phys Lett 1999; 74: 317-9.

40. Nozik AJ. Nanoscience and nanostructures for photovoltaics and solar fuels. Nano Lett 2010; 10: 2735-41.

41. Semonin OE, Luther JM, Choi S, Chen H-Y, Gao J, Nozik AJ, et al. Peak external photocurrent quantum efficiency exceeding $100 \%$ via MEG in a quantum dot solar cell. Science $2011 ; 334$ : 1530-3.

42. Beard MC. Multiple exciton generation in semiconductor quantum dots. J Phys Chem Lett 2011; 2: 1282-8.

43. Huang X, Huang S, Zhang Q, Guo X, Li D, Luo Y, et al. A flexible photoelectrode for CdS/CdSe quantum dot-sensitized solar cells (QDSSCs). Chem Commun 2011; 47: 2664 -6.

44. Yang Z, Zhang Q, Xi J, Park K, Xu X, Liang Z, et al. CdS/CdSe co-sensitized $\mathrm{TiO} 2$ solar cell prepared by jointly using the successive ion layer absorption and reaction (SILAR) method and chemical bath deposition (CBD) process. Sci Adv Mater 2012; 4: 1013-7.

45. Etgar L. Semiconductor nanocrystals as light harvesters in solar cells. Materials 2013; 6: 445-59.

46. Hossain MA, James RJ, Shen C, Jia PH, Koh ZY, Mathews N, et al. CdSe-sensitized mesoscopic $\mathrm{TiO} 2$ solar cells exhibiting $>5 \%$ efficiency: redundancy of CdS buffer layer. J Mater Chem 2012; 22: 16235-42.

47. Lee J-W, Son D-Y, Ahn TK, Shin H-W, Kim IY, Hwang S-J, et al. Quantum-dot-sensitized solar cell with unprecedentedly high photocurrent. Sci Rep 2013; 3: 1050.

48. Chou TP, Zhang QF, Fryxell GE, Cao GZ. Hierarchically structured $\mathrm{ZnO}$ film for dye-sensitized solar cells with enhanced energy conversion efficiency. Adv Mater 2007; 19: 2588-92.

49. Zhang QF, Cao GZ. Hierarchically structured photoelectrodes for dye-sensitized solar cells. J Mater Chem 2011; 21: 6769-74.

50. Zhang QF, Chou TR, Russo B, Jenekhe SA, Cao GZ. Aggregation of $\mathrm{ZnO}$ nanocrystallites for high conversion efficiency in dye-sensitized solar cells. Angew Chem Int Ed 2008; 47: 2402-6.

51. Zhang QF, Dandeneau CS, Zhou XY, Cao GZ. ZnO nanostructures for dye-sensitized solar cells. Adv Mater 2009; 21: 4087-108.

52. Zhang QF, Yodyingyong S, Xi JT, Myers D, Cao GZ. Oxide nanowires for solar cell applications. Nanoscale 2012; 4: 1436-45.

53. Seol M, Kim H, Tak Y, Yong K. Novel nanowire array based highly efficient quantum dot sensitized solar cell. Chem Commun 2010; 46: 5521-3.
54. Seol M, Ramasamy E, Lee J, Yong K. Highly efficient and durable quantum dot sensitized $\mathrm{ZnO}$ nanowire solar cell using noble-metal-free counter electrode. J Phys Chem C 2011; 115: 22018-24.

55. Yao C-Z, Wei B-H, Meng L-X, Li H, Gong Q-J, Sun H, et al. Controllable electrochemical synthesis and photovoltaic performance of $\mathrm{ZnO} / \mathrm{CdS}$ core-shell nanorod arrays on fluorine-doped tin oxide. J Power Sources 2012; 207: 222-8.

56. Bora T, Kyaw HH, Dutta J. Zinc oxide-zinc stannate core-shell nanorod arrays for CdS quantum dot sensitized solar cells. Electrochim Acta 2012; 68: 141-5.

57. Cheng HM, Huang KY, Lee KM, Yu P, Lin SC, Huang $\mathrm{JH}$, et al. High-efficiency cascade $\mathrm{CdS} / \mathrm{CdSe}$ quantum dotsensitized solar cells based on hierarchical tetrapod-like $\mathrm{ZnO}$ nanoparticles. Phys Chem Chem Phys 2012; 14: 13539-48.

58. Tian JJ, Zhang QF, Zhang LL, Gao R, Shen LF, Zhang SG, et al. $\mathrm{ZnO} / \mathrm{TiO}_{2}$ nanocable structured photoelectrodes for CdS/ CdSe quantum dot co-sensitized solar cells. Nanoscale 2013; 5: 936-43.

59. Tian JJ, Zhang QF, Zhang LL, Gao R, Shen LF, Zhang SG, et al. Energy materials: core/shell structural photoelectrodes assembled with quantum dots for solar cells. Nano Rev 2013; 4: 21080 .

60. Irannejad A, Janghorban K, Tan OK, Huang H, Lim CK, Tan PY, et al. Effect of the $\mathrm{TiO}_{2}$ shell thickness on the dye-sensitized solar cells with $\mathrm{ZnO}-\mathrm{TiO}_{2}$ core-shell nanorod electrodes. Electrochim Acta 2011; 58: 19-24.

61. Tian JJ, Zhang QF, Uchaker E, Gao R, Qu XH, Zhang SG, et al. Architectured $\mathrm{ZnO}$ photoelectrode for high efficiency quantum dot sensitized solar cells. Energy Environ Sci 2013, in press; DOI: 10.1039/C3EE41056K.

62. Tian JJ, Zhang QF, Uchaker E, Liang ZQ, Gao R, Qu XH, et al. Constructing $\mathrm{ZnO}$ nanorod array photoelectrodes for highly efficient quantum dot sensitized solar cells. J Mater Chem A 2013; 1: 6770-5.

\author{
*Jianjun Tian \\ Advanced Materials and Technology Institute \\ University of Science and Technology Beijing \\ 30 Xueyuan Road, Beijing 100083, China \\ Email: tianjianjun@mater.ustb.edu.cn

\section{*Guozhong Cao} \\ Department of Materials and Engineering \\ University of Washington, Seattle, WA 98195, USA \\ Email: gzcao@u.washington.edu
}

